other was an attempt to communicate developments so far with a District-wide audience convened by the Unit General Manager, including some Social Services personnel.

The seminar involving a wider audience began with a brief presentation of the main findings of the Interim Report by the authors. This was followed by some observations from the Cosham team on 'the experience of being researched' during this period of transition. There was general agreement that having an 'independent view' was helpful in encouraging an atmosphere of questioning and reflection, enabling them to see more clearly some of the issues underlying their day-to-day activities.

The second half of the programme was more specifically structured to facilitate both informationsharing and learning across local area and professional boundaries. Small groups, deliberately including managers and practitioners from different disciplines and areas, were invited to discuss the two key issues identified above, to which we added the question of how to provide for ongoing systematic review. This was followed by a plenary discussion, during which the main points from each group were shared and brought together.

Becoming more actively and directly involved in the dissemination process, and in encouraging participants to identify general learning points from the particular experience of one local service, is a relatively new experience for us as researchers. We would, however, argue the need for such initiatives in the context of researching organisational change. Planning for change inevitably involves uncertainty:

Planning should be a continuous process of generating and testing ideas, with review and feedback mechanisms built into the system as key features (Kingsley \& Towell, 1988, p. 67).

There are many ways in which the experience of service development can be used as learning for subsequent initiatives. In this paper we have tried to exemplify an approach to evaluation which can directly contribute to the ongoing process of service development, in this case assisting a service actively engaged in establishing comprehensive and locally based mental health facilities.

\section{References}

KIngsley, S. \& Towell, D. (1988) Planning for high quality local services. In Community Care in Practice: Services for the Continuing Care Client. (eds A Lavender and F. Holloway). Chichester: Wiley, pp. 51-74.

MCKEE, L. (1988) Conflicts and context in managing the closure of a large psychiatric hospital. Bulletin of the Royal College of Psychiatrists, 12, 310-319.

ØVRETVEIT, J. (1986) Organisation of Multidisciplinary Community Teams. Uxbridge: BIOSS, Brunel University. -, Temple, H. \& Coleman, R. (1988) The Organisation - and Management of Community Mental Health Teams. London/Guildford: Good Practices in Mental Health/ Interdisciplinary Association of Mental Health Workers.

Phillips, D., BARRIT, A., BOOTH, T., JoNEs, D. et al (1988) Classifying psychiatric crises: problems of reliability in post-coding open-ended questions. Research, Policy and Planning, 6, 1-6.

Powell, J. \& Lovelock, R. (1989) Cosham Mental Health Service Evaluation: Interim Report. Southampton, University of Southampton.

A full list of references is available on request from the authors.

\title{
To all current and ex members of the Association of University Teachers of Psychiatry
}

The Association receives each year over 100 sums of $£ 1$ or $£ 2$ as a result of standing orders which have never been cancelled. In the case of those members who are also paying the full subscription of $£ 10$ and remain on the membership list we can write to them advising them to cancel their additional subscription. However, in the case of the others we have no means of tracing their identities and reminding them to cancel the accounts. We therefore have to treat the sums involved as donations which we are unable to refund. I would ask all ex-members of the Association who are not paying the current $£ 10$ annual subscription on 1 July to contact their banks and either cancel their standing orders or increase them to $£ 10$ and send me a cheque for the balance of this year with sufficient details for me to fill out a new membership form, i.e. including departmental address and address for correspondence.

Alex Kellam

University Hospital of Wales Treasurer, AUTP 